๑ О. Л. Благодір, аспірантка, О. М. Величко, д.т.н., професор, Т. Г. Осипова, к.т.н., доцент, НТУУ «КПІ», Київ, Україна

\title{
ВПЛИВ ОДНОЧАСНОї ДІї УФ-ОПРОМІНЕННЯ І МАГНІТНОГО ПОЛЯ У ПРОЦЕСАХ РЕЄСТРАЦІЇ ІНФОРМАЦІЇ
}

Встановлено взаємовплив параметрів УФ-опромінення i магнітного поля на твердіння фотополімеризаційноздатних шарів для підвищення продуктивності технологічного процесу реєстрації інформації.

Ключові слова: УФ-опромінення; магнітне поле; фотополімеризація; реєстрація інформації.

\section{Постановка проблеми}

Інтенсифікація структурних перетворень в фотополімеризаційноздатних шарах для підвищення продуктивності процесів реєстрації зображень у формних процесах та закріплення відбитків УФ-фарб і УФ-лаків у процесах друкування продовжує бути актуальним завданням, оскільки домінує застосування високо технологічного автоматизованого і комп'ютеризованого обладнання, яке забезпечує об'єднання у єдиний продуктивний цикл формно-друкарські та обробні процеси. Саме переваги потокового виробництва сприяють стабільній продуктивності сучасного устаткування незалежно від зменшення накладів поліграфічної продукції і урізноманітнення її конструкційних елементів.

\section{Аналіз попередніх досліджень}

Відомі дослідження структурних змін залежно від складу й товщини фотополімеризаційноздатних шарів та режимів їх УФ-опромінення [1-6] розвинули технологічні основи формування і реєстрації зображень у формних та друкарсько-обробних процесах флексографічного, трафаретного, офсетного способів друку.

Сутність досліджень увиразнила технічні можливості управління процесом реєстрації і закріплення зображення, що в цілому дало поштовх розширенню складників та варіантів їх компонування у композиціях лаків, фарб та копіювальних шарів. Однак, як було встановлено в [4, 6], продуктивність процесу у потоці із застосуванням високо технологічного обладнання не забезпечується в повній мірі.

Відомі й поширені технічні засоби і методи підвищення продуктивності процесів полімеризації шляхом одночасного впливу електромагнітного поля різної частоти, потужності і часу 


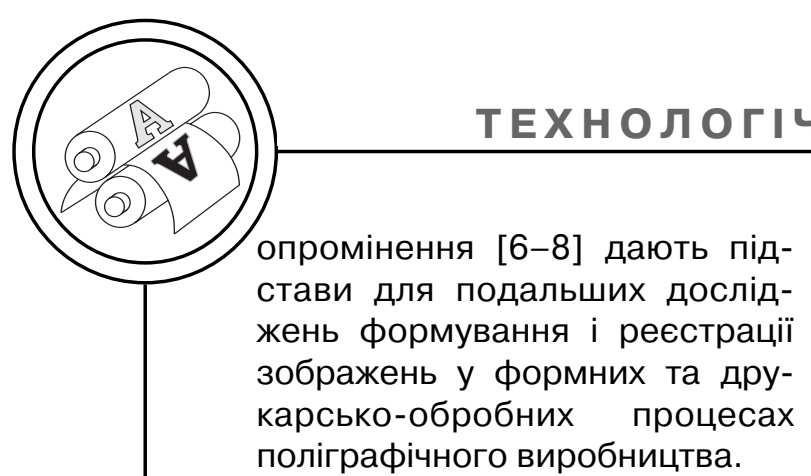

\section{Мета роботи}

Мета даного дослідження встановлення взаємовпливу параметрів УФ-опромінення i магнітного поля під час формування і реєстрації зображень у фотополімеризаційноздатних шарах на основі олігоефіракрилатних композицій, що у подальшому дасть можливість сформулювати науково обґрунтовані рекомендації для забезпечення закріплення відбитків у процесах друкування 3 анілоксовими системами.

\section{Результати проведених досліджень}

Для випробувань було створено модельну фотополімеризаційноздатну композицію на основі суміші олігоефіракрилатів марок ТГМ-3 та МГФ-9 у співвідношенні 1:1, фотоініціатора та гідрохінона. Визначення умовної в'язкості проводили за В3-246 (4 мм) згідно ГОСТ 8420-74. Встановлено в'язкість у межах 25-50 с, що відповідає властивостям більшості УФ-лаків, а також УФ-фарб для флексографічного друку та копіювальним шарам для трафаретних друкарських форм.

Модельна установка для опромінення УФ-композицій і одночасного упливу магнітного поля складалася 3 П-подібної конструкції електромагніта для створення магнітного поля, лампи ЛУФ-80 та підставки для розміщення опромінювальних об'єктів. Варіювали режими оброблення: струм від 1 до 5 a; напрям упливу магнітного поля перпендикулярно і паралельно напряму опромінення об'єктів. Час опромінення постійний 30 хв. та відстань від об'єктів до УФ-лампи і джерела магнітного поля $15 \mathrm{~cm}$.

Дослідження структурних змін в модельних зразках проводили за допомогою метода інфрачервоної спектроскопії багаторазового повного порушеного внутрішнього відбивання на 14-спектрофотометрі UR-20 $[9,10]$.

Вивчали спектрограми і розраховували інтенсивність максимумів порівняно з базовою лінією у відсотках.

Аналіз спектрограм модельних зразків за [11] виявив суттєвий вплив магнітного поля на прискорення реакції фотополімеризації. В результаті взаємодії реакційноздатних і функціональних груп та розриву подвійних зв'язків змінюються інтенсивність і форми максимумів частот відбивання.

У спектрограмах затверділих фотополімеризаційноздатних шарів спостерігаються зміни в максимумах частот 710-760; $840 ; 1280 ; 1340 ; 1410-1460$; $1620-1680 \mathrm{~cm}^{-1}$ в бік зменшення поглинання порівняно 3 необробленими магнітним полем.

Наприклад, смуги 710-760; $840 \mathrm{~cm}^{-1}$ характеризують деформаційні коливання зв'язків $\mathrm{C}-\mathrm{C}$ і груп $\left(\mathrm{CH}_{2}\right)_{4}$ довгих ланцюгів і перехід у твердий стан. Смуги 1280; 1340 см$^{-1}$ характеризують деформаційні 
коливання груп $\mathrm{CH}_{3} ; \mathrm{CH}$; а смуги 1410-1460 см-1 - деформаційні груп $\mathrm{CH}_{2} ; \mathrm{CH}_{3}, 1620-$ $1680 \mathrm{~cm}^{-1}$ - валентні коливання зв'язків $\mathrm{C}=\mathrm{C}$.

Загалом виявлені зміни свідчать про інтенсифікацію розриву макромолекулярних ланцюгів і утворення просторово-розгалуженої сітчастої структури, тобто пришвидшення переходу з рідкого стану в твердий. При цьому спостерігається суттєвий вплив малопотужного магнітного поля.

Як видно з рис., найбільш ефективний режим одночасного УФ-опромінення і магнітного поля, створюваного струмом 1 i
2 а подальше підвищення струму в межах 3-5 а призводить до зниження інтенсивності. За даними рис. можна твердити про ефективність струму в 1 а, деяку стабілізацію змін при 2-3 а, і зниження ефекту при 4-5 а. Проте, струм 1 а для створення магнітного поля цілком достатньо для вивчених режимів упливу - лампа ЛУФ-80, час опромінювання 30 хв., віддаль від джерела до об'єктів 15 см.

Напрям упливу магнітного поля - перпендикулярно і паралельно напряму опромінення, не відіграє практичної ролі зміни ідентичні в обох напрямках.

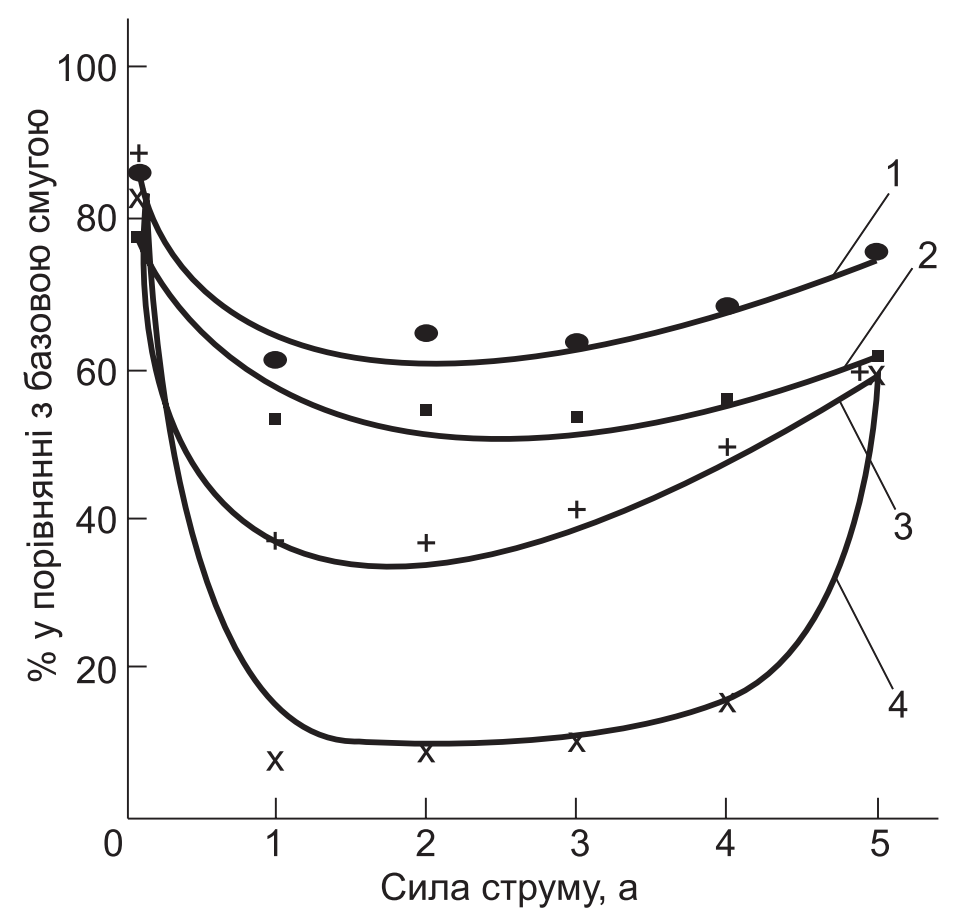

$(x)-720 ;(+)-980 ;(\cdot)-1660 ;(\bullet)-820 \mathrm{~cm}^{-1}$;

Зміни інтенсивності смуг поглинання порівняно з базовою залежно від сили струму: $1-820 \mathrm{~cm}^{-1} ; 2-1660 \mathrm{~cm}^{-1} ; 3-980 \mathrm{~cm}^{-1} ; 4-720 \mathrm{~cm}^{-1}$ 


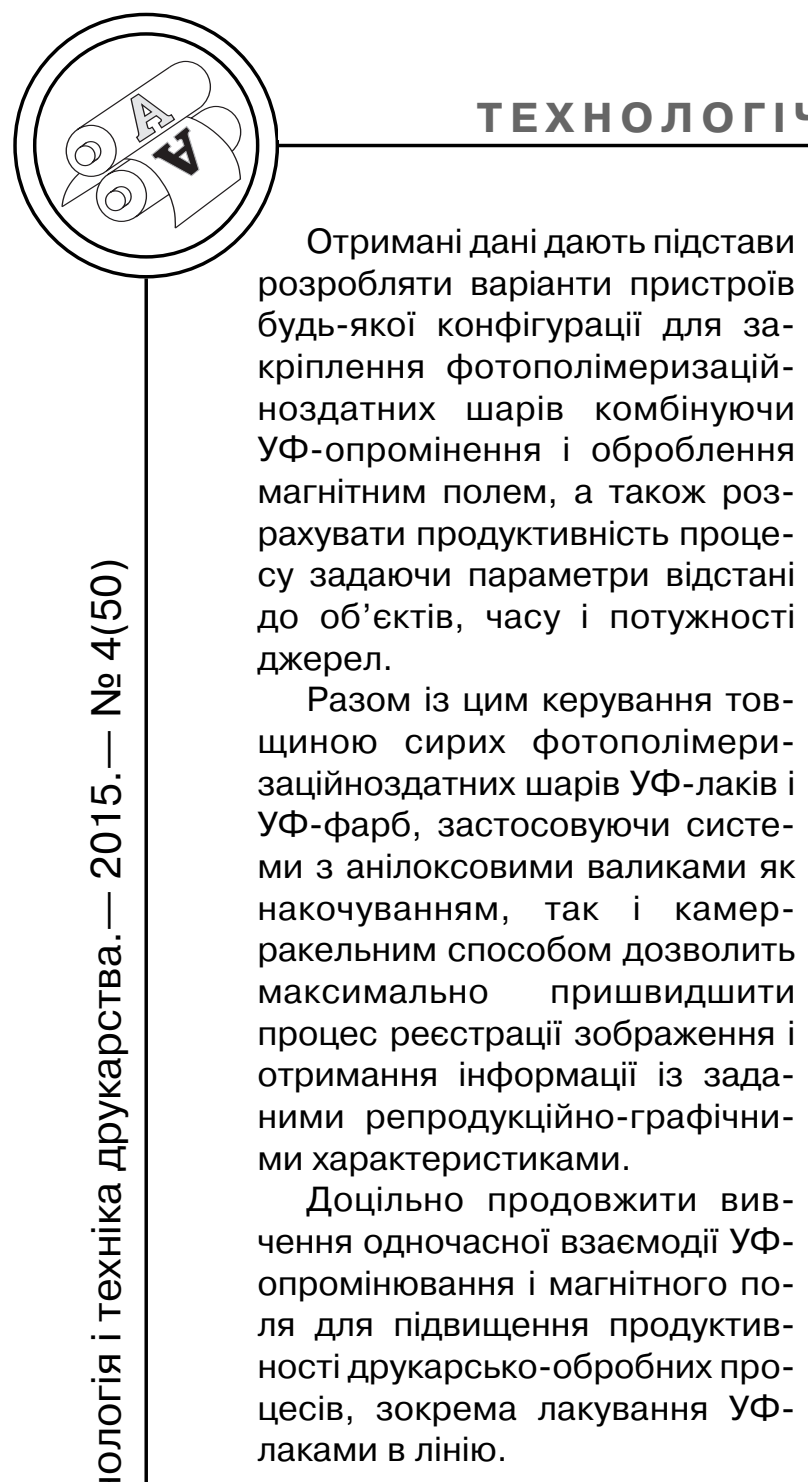

\section{Висновки}

1. Проведено дослідження одночасного впливу УФ-опромінювання і магнітного поля, створеного електромагнітом 3 регулюванням сили струму, на твердіння фотополімеризаційноздатних шарів на основі олігоефіракрилатів і встановлено ефективність дії магнітного поля, заданого струмом в 1 a, практично незалежно від напрямку його дії.

2. Результати дослідження сприяють розробленню пристроїв будь-якої конфігурації для закріплення фотополімеризаційноздатних шарів комбінуючи УФ-опромінення і оброблення магнітним полем.

3. Задаючи параметри відстані до об'єктів, часу і потужності джерел УФ-опромінювання і магнітного поля можливо розрахувати продуктивність процесу для прогнозування керування товщиною сирих фотополімеризаційноздатних шарів УФ-лаків і УФ-фарб, застосовуючи системи з анілоксовими валиками як накочуванням, так і камер-ракельним способом.

\section{Список використаної літератури}

1. Шибанов В. В. Фотополімеризаційноздатні матеріали / В. В. Шибанов. - Львів : УАД, 2008. -216 с.

2. Климова Е. Д. Фотополимеризующиеся композиции для печатных и отделочных процессов / Е. Д. Климова. - М. : МГУП, 2000. - 192 с.

3. Шибанов В. В. Флексографічні фотополімерні форми / В. В. Шибанов. - Львів : УАД, 2011. - 116 с.

4. Хохлова Р. А. Лакування у друкарсько-обробному процесі / Р. А. Хохлова, О. М. Величко : Моногр. - К. : ВПЦ «Київський університет», 2010. $163 \mathrm{c}$.

5. Репета В. Б. Матеріали і технології лакування поліграфічної продукції / В. Б. Репета, В. В. Шибанов. - Львів : УАД, 2011. - 136 с.

6. Хохлова Р. А. Оздоблення поліграфічної продукції лакуванням / Р. А. Хохлова, О. М. Величко : навч. посіб. - К. : ВПЦ «Київський університет», 2014. $-183 \mathrm{c}$.

7. Мещерякова Т. М. Матеріалознавство / Т. М. Мещерякова, Р. А. Яцюк, О. А. Кузін, М. О. Кузін : підруч. - Дрогобич : Коло, 2015. - 400 с. 
8. Шибанов В. В. Фотохімія. Навч. посіб. Частина 2. Лабораторні роботи / В. В. Шибанов, І. Й. Маршалок : навч. посіб. - Львів : УАД, 2008. - 132 с.

9. Тугов И. И. Химия и физика полимеров / И. И. Тугов, Г. И. Кострыкина : учеб. пособ. - М. : Химия, 1989. - с. 76. - Назв. с экрана. Ресурс доступа: https://books.google.com.ua/books?id=PV_ 9AgAAQBAJ\&printsec=frontcover \&hl=ru\#v=onepage\&q\&f=false.

10. Бёккер Ю. Мир химии. Спектроскопия / Пер. с нем. Л. Н. Казанцевой, под ред. А. А. Пупышева, М. В. Поляковой. - М. : Техносфера, 2009. 528 с. - Назв. с экрана. Ресурс доступа : С. 171-175: https://books.google.com.ua/books?id=4QrOAAAAQBAJ\&printsec=frontcover\&hl=ru\&source=gbs_ge_summary_r\&cad=0\#v=onepage\&q\&f=false.

11. Дехант И. Инфракрасная спектроскопия полимеров / И. Дехант, Р. Данц, В. Киммер, Р. Шмальке. - М. : Химия. - 1976. - С. 22-24, 80-90.

\section{References}

1. Shybanov V. V. Fotopolimeryzatsiinozdatni materialy / V. V. Shybanov. Lviv : UAD, 2008. - $216 \mathrm{~s}$.

2. Klimova E. D. Fotopolimerizujushhiesja kompozicii dlja pechatnyh i otdelochnyh processov / E. D. Klimova. - M. : MGUP, 2000. - 192 s.

3. Shybanov V. V. Fleksohrafichni fotopolimerni formy / V. V. Shybanov. - Lviv : UAD, 2011. - $116 \mathrm{~s}$.

4. Khokhlova R. A. Lakuvannia u drukarsko-obrobnomu protsesi / R. A. Khokhlova, O. M. Velychko : Monohr. - K. : VPTs «Kyivskyi universytet», 2010. - $163 \mathrm{~s}$.

5. Repeta V. B. Materialy i tekhnolohii lakuvannia polihrafichnoi produktsii / V. B. Repeta, V. V. Shybanov. - Lviv : UAD, 2011. - $136 \mathrm{~s}$.

6. Khokhlova R. A. Ozdoblennia polihrafichnoi produktsii lakuvanniam / R. A. Khokhlova, O. M. Velychko : navch. posib. - K. : VPTs «Kyivskyi universytet», 2014. $-183 \mathrm{~s}$.

7. Meshcheriakova T. M. Materialoznavstvo / T. M. Meshcheriakova, R. A. Yatsiuk, O. A. Kuzin, M. O. Kuzin : pidruch. - Drohobych : Kolo, 2015. $400 \mathrm{~s}$.

8. Shybanov V. V. Fotokhimiia. Navch. posib. Chastyna 2. Laboratorni roboty / V. V. Shybanov, I. I. Marshalok : navch. posib. - Lviv : UAD, 2008. - 132 s.

9. Tugov I. I. Himija i fizika polimerov / I. I. Tugov, G. I. Kostrykina : ucheb. posob. - M. : Himija, 1989. - s. 76. - Nazv. s jekrana. Resurs dostupa: https://books.google.com.ua/books?id=PV_ 9AgAAQBAJ\&printsec=frontcover\&hl $=r u \# v=$ onepage $\& q \& f=$ false.

10. Bjokker Ju. Mir himii. Spektroskopija / Per. s nem. L. N. Kazancevoj, pod red. A. A. Pupysheva, M. V. Poljakovoj. - M. : Tehnosfera, 2009. - 528 s. Nazv. s jekrana. Resurs dostupa : S. 171-175: https://books.google.com.ua/ books?id=4QrOAAAAQBAJ\&printsec=frontcover\&hl=ru\&source=gbs_ge_summary_r\&cad $=0 \# v=$ onepage $\& q \& f=f a l s e$.

11. Dehant I. Infrakrasnaja spektroskopija polimerov / I. Dehant, R. Danc, V. Kimmer, R. Shmal'ke. - M. : Himija. - 1976. - S. 22-24, 80-90.

Установлена взаимосвязь параметров УФ-облучения и одновременного действия магнитного поля на процесс отверждения фотополимеризующихся слоев для повышения производительности технологического процесса регистрации информации. 


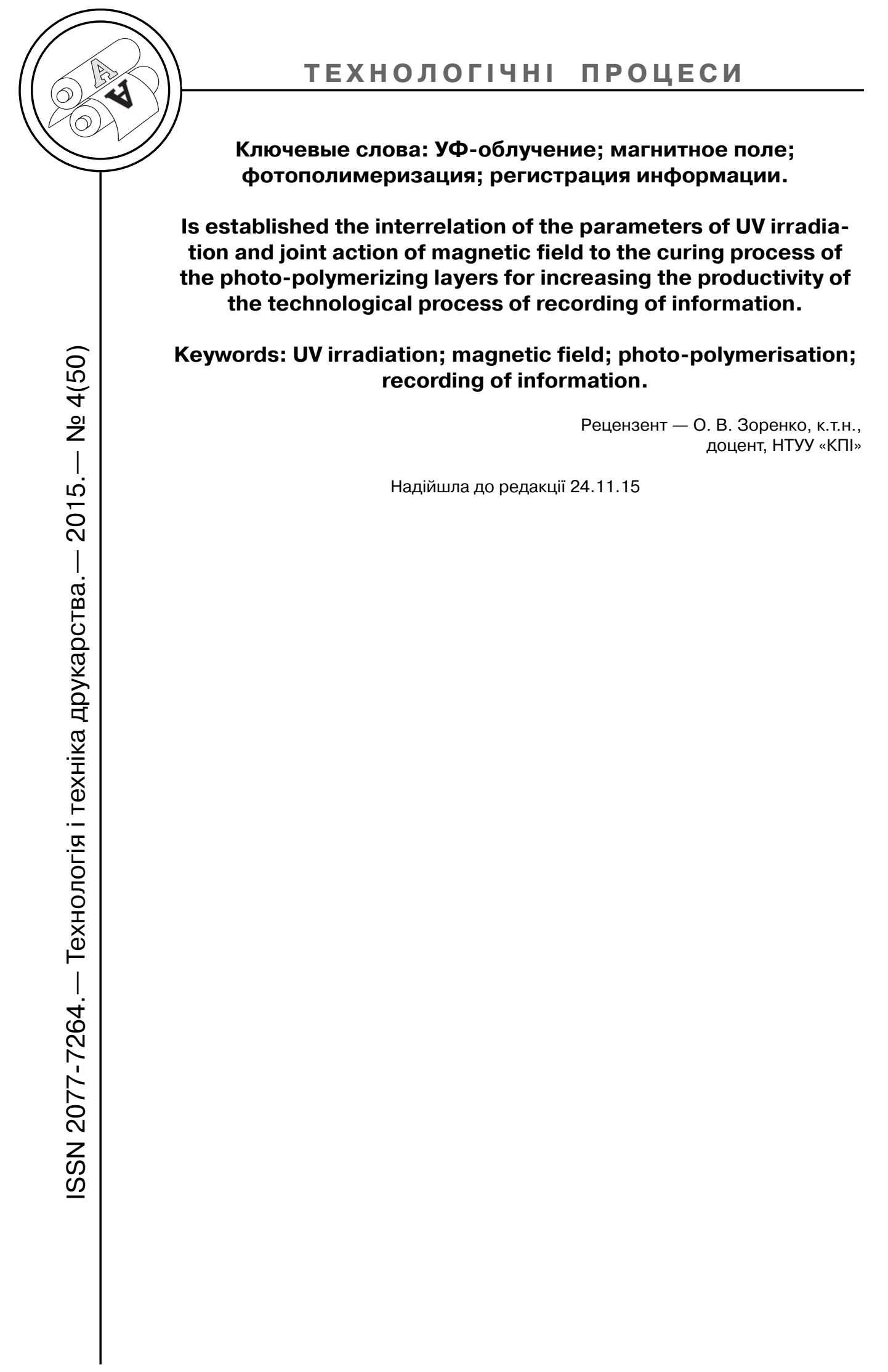

